\title{
Mechanistic Study of Adsorption of Acid Orange-7 over Aluminum Oxide Nanoparticles
}

\author{
Ekta Khosla, ${ }^{1}$ Satindar Kaur, ${ }^{2}$ and Pragnesh N. Dave ${ }^{3}$ \\ ${ }^{1}$ Department of Chemistry, Hans Raj Mahila Maha Vidyalaya, Jalandhar, Punjab 144021, India \\ ${ }^{2}$ Department of Food Sciences \& Technology, Guru Nanak Dev University, Amritsar, Punjab 143005, India \\ ${ }^{3}$ Krantiguru Shyamji Krishna Verma Kachchh University, Mundra Road, Bhuj, Gujarat 370001, India
}

Correspondence should be addressed to Pragnesh N. Dave; pragnesh7@yahoo.com

Received 24 November 2012; Accepted 5 December 2012

Academic Editor: Jose M. Guisan

Copyright (C) 2013 Ekta Khosla et al. This is an open access article distributed under the Creative Commons Attribution License, which permits unrestricted use, distribution, and reproduction in any medium, provided the original work is properly cited.

\begin{abstract}
The adsorption behavior of acid orange-7 (AO-7) on aluminum oxide nanoparticles (ANP) generated by sol-gel method has been investigated to understand the physicochemical process involved and to explore the potential use of nano particles in textile effluent treatment and management. The results revealed that ANP can remove AO-7 dye up to $97.6 \mathrm{mg} / \mathrm{g}$ at $303 \mathrm{~K}$. The adsorption process is found to be $\mathrm{pH}$ dependent and the optimum $\mathrm{pH}$ obtained is 2.0. The equilibrium was established in $1 \mathrm{~h}$. Langmuir, Freundlich, and Temkin Isotherm models were applied on the system. Scanning electron microscopic analysis reveals eye-catching nanoporous morphology of the material. The results of FTIR spectroscopy reveal that the process is electrostatic complexation mechanism driven. XRD studies revealed nanocrystalline structure of ANP. BET surface area measurement suggests high pore volume and surface area of adsorbent. The kinetic measurements suggest pseudo-second-order kinetic processes. The thermodynamic measurements suggest that all processes are endothermic accompanied with negative $\Delta G^{\circ}$ and positive $\Delta S^{\circ}, \Delta H^{\circ}$.
\end{abstract}

\section{Introduction}

It is well recognized that the presence of dyes in aquatic environment can result in several problems. Most dyes are soluble in water. Textile waste water is one of the major environmental concerns. Many industries use dyes and pigments to color their final products. Consequently the waste water effluents are highly colored and the disposal of this waste in water bodies causes damage to the environment. These dyes affect photosynthetic activities of aquatic flora due to reduced penetration of sun light. Most of the dyes are xenobiotic and nonbiodegradable in nature. The conventional waste water treatment technologies depend upon removal of biological oxygen demand but reduction of BOD is ineffective against color removal. The combination of technologies like adsorption and dye degradation can provide the solution to the problem [1], although these processes are still in laboratory stage of development. Chemical oxidation of dyes is very successful for azo dyes as it can initiate the cleavage of azo bond. The problem of secondary pollution due to formation of oxidized amines and chlorine (in case of $\mathrm{NaOCl}$ ) is suspected [2]. In recent times $\mathrm{UV} / \mathrm{O}_{3}$ has been used as treatment technology. This is applicable in gaseous state and almost all types of dyes can be removed successfully without formation of any sludge. The process is $\mathrm{pH}$ dependent and associated with high cost and also suffers from limitation of UV-light penetration $[3,4]$. Sonoelectrolysis is also evaluated for the azo dye removal. The electrooxidation of dye $(50 \mathrm{ppm})$ in saline solution involving in situ generation of hypochlorite ion was enhanced using ultrasound $(20 \mathrm{kHz}, 22 \mathrm{w})$ when carried out in a semisealed cell which reduced the ultrasonic degassing [5]. Adsorption is a conventional technology for dye removal with very high efficiency and simple process. Granulated activated carbon is used for the removal of azo dye, acid orange-7 from aqueous solution [6]. The carbon is regenerated using microwave radiations. The efficiency of carbon was very high due to surface modification. Activated carbon is very efficient adsorbent and very efficient for cationic and anionic dyes. The adsorbent use of carbon in wastewater treatment is impractical due to competitive adsorption of other organic molecules along with dye molecules; the carbon as adsorbent 


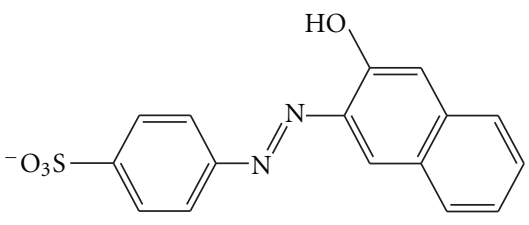

Figure 1: Structure of AO-7.

can be thus used in end of treatment steps exclusively for color removal. The nonconventional adsorbents are in application due to their easy availability [7]. Agricultural and industrial waste products with and without modification are efficient in removing color [8-12]. The sludge disposal problem is a setback hence recyclable and more efficient adsorbents are required [13]. Adsorption technology is nondestructive technology involving phase change from aqueous phase to solid surface immobilization. Some techniques involving adsorption with catalytic degradation of dye seem to be more lucrative. Chen et al. [14] removed aromatic compounds on single-walled carbon nanotubes. The application of nanoparticles as adsorbents has come up as an interesting area of research because of their small particle size and high surface area. The active sites are also more and capable of interacting with pollutant species $[15,16]$. The application of ANP has been evaluated for the removal of hexavalent chromium from aqueous medium [17]. A previous study indicates that adsorption capacity remains unchanged after regeneration of nanosized adsorbent [18]. ANPs are prepared by using solgel method. The material of high purity can be prepared by this method [19]. In the present study ANPs prepared by solgel method are used for adsorptive removal of azo dye AO-7 from aqueous medium.

\section{Materials and Methods}

2.1. Preparation of Dye Solution. Acid orange 7 was procured from Thomas Baker Company and used without any purification. The structure of dye is given in Figure 1. Acid orange7 (AO-7) or orange-II dye is an anionic azo dye. Its IUPAC name is sodium 4-[(2-hydroxy-1-naphthyl)azo]benzene sulfonate. Its molecular mass is 350.3 (327.3 for anion) with molecular formula $\mathrm{C}_{16} \mathrm{H}_{11} \mathrm{~N}_{2} \mathrm{NaSO}_{4}$. It is orange-colored powder soluble in water. Its C.I. number is 15510 . It is used for dying variety of materials of nylon, silk, and wool. It is highly toxic and its ingestion may cause eye, skin, mucous membrane, and upper respiratory tract irritation. Its intake may cause cancer due to its carcinogenic nature [20]. This dye shows $\lambda_{\max }$ at $542 \mathrm{~nm} .1000 \mathrm{ppm}\left(1000 \mathrm{mg} \mathrm{L}^{-1}\right)$ solutions were prepared by dissolving appropriate amount of dye in water and stored in dark colored bottle and diluted by adding suitable amount of distilled water to the stock solution as per requirement.

2.2. Preparation of Nanoparticles. Nano- $\mathrm{Al}_{2} \mathrm{O}_{3}$ particles (ANP) were synthesized by sol-gel method [17]. For this purpose saturated solution of aluminium sulphate was precipitated with $6 \mathrm{~N}$ ammonia solution till a gel is obtained. The gel is then calcined in a muffle furnace at $1073 \mathrm{~K}$ for $1 \mathrm{~h}$. The powder ANP was stored in a dessicator till further use.

2.3. Adsorption Experiments. The series of experiments were conducted by placing $50 \mathrm{~mL}$ of $100 \mathrm{ppm}$ dye solution in an Erlenmeyer flask and adding the required amount of adsorbent to that in an incubator shaker. The $\mathrm{pH}$ of different solutions was adjusted with $0.1 \mathrm{~N} \mathrm{HCl}$ and $0.1 \mathrm{~N} \mathrm{NaOH}$. After attainment of equilibrium the aqueous phase was analyzed for residual dye concentration using UV visible spectrophotometer. From the absorbance data $q_{e}\left(\mathrm{mgg}^{-1}\right)$ was determined using

$$
q_{e}=\frac{\left(C_{0}-C_{e}\right) V}{W}
$$

where $C_{0}$ is initial dye concentration, $C_{e}$ is final dye concentration, and $V$ is volume of dye in liters and $W$ is mass of adsorbent in $\mathrm{g}$. Duplicate experiments were performed to get concordant results. The results showed variation in the range of $\pm 5 \%$. The kinetics of dye removal was studied using required dye concentration. The samples were withdrawn at regular intervals and residual concentration was analyzed after centrifugation using ultracentrifugation at $1000 \mathrm{rpm}$. The isotherms were studied by using $50 \mathrm{~mL}$ of dye solution within optimum range of concentration at $303 \mathrm{~K}, 313 \mathrm{~K}$, and $323 \mathrm{~K}$. After the attainment of equilibrium the residual dye concentration was analyzed spectrophotometrically. The dye concentration before and after adsorption was determined by using Shimadzu (2101 PC) spectrophotometer. A standard plot is drawn for known concentrations and the concentration of dyes was determined by converting the optical density to corresponding concentration. The dyes were analyzed at their respective $\lambda_{\text {max }}$. The $\mathrm{pH}_{\mathrm{zpc}}$ ( $\mathrm{pH}$ zero point charge) was determined by the method reported earlier [3]. The $\mathrm{pH}$ of dye solutions and $\mathrm{pH}_{\mathrm{zpc}}$ were determined by using $\mathrm{pH}$ meter by Toshvin (TMP-85). An autoarranging conductivity meter $\mathrm{TCM}+15$, provided with temperature compensator made by Toshnival, India, was used for determination of surfactant characteristics and nature of the filtrate of adsorbent and its derivative washings. The weighing was carried out on a digital weighing balance of accuracy up to $0.1 \mathrm{mg}$ by citizen Co. BET surface area measurement is carried out by using micrometrics surface area analyzer. This also gave monolayer volume of $\mathrm{N}_{2}$ and pore volume of the adsorbents. The FTIR of adsorbents and surface derivatives was carried out with Perkin Elmer spectrophotometer in the range of $400-4000 \mathrm{~cm}^{-1}$ using perkin elmer spectrophotometer. The adsorbent is mixed with anhydrous $\mathrm{KBr}$ to make a pellet and 400 scans are carried out to give the average FTIR scan. The adsorbent samples were also characterized by powder X-ray diffractometry using an X'PERT PRO PANalytical with $\mathrm{Cu}-\mathrm{K}_{\alpha}$ radiation. SEM is carried out by using ZEOL scanning electron micrograph. TEM provided topographical, morphological, compositional, and crystalline information of nanoadsorbents. The images allow us to view samples on a molecular level, making it possible to analyze structure and texture. The data analysis was carried out by using correlation 


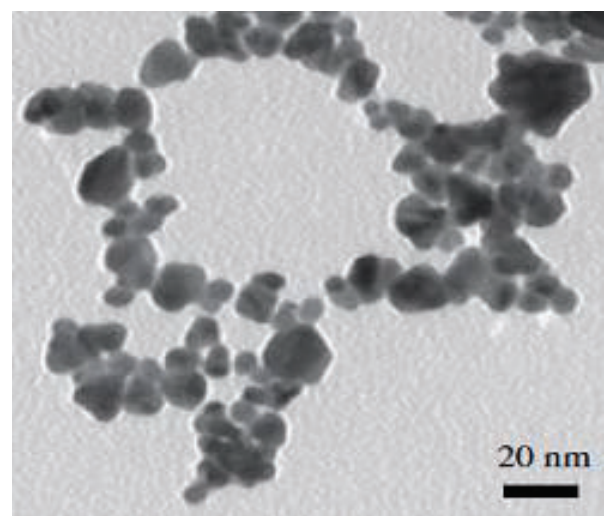

(a)

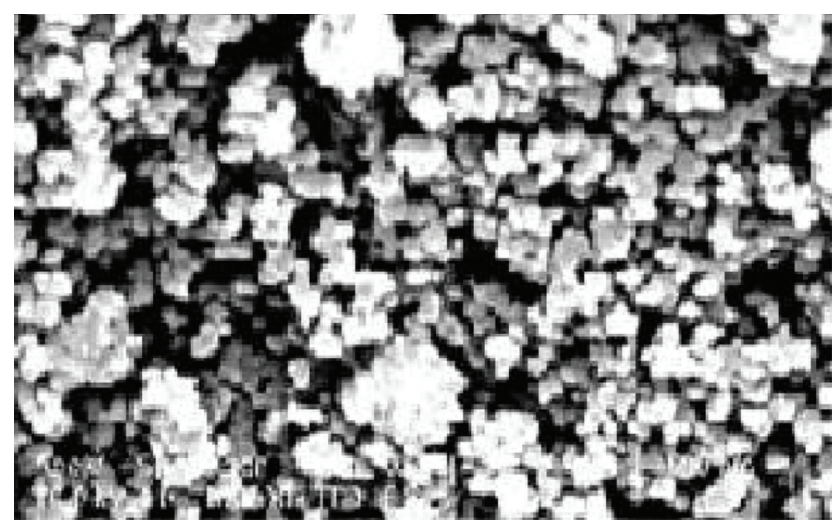

(b)

Figure 2: (a) TEM of ANP. (b) SEM of ANP.

TABLE 1: Characteristics of ANP.

\begin{tabular}{lc}
\hline Surface area $\left(\mathrm{m}^{2} \mathrm{~g}^{-1}\right)$ & 82.91 \\
Bulk density $\left(\mathrm{g} \mathrm{mL}^{-1}\right)$ & 0.976 \\
Zero point charge $\left(\mathrm{pH}_{\mathrm{zpc}}\right)$ & 8.0 \\
Total surface acidity $\left(\mathrm{mmol} \mathrm{g}^{-1}\right)$ & 0.253 \\
Total surface basicity $\left(\mathrm{mmol} \mathrm{g}^{-1}\right)$ & 6.879 \\
\hline
\end{tabular}

analysis employing least squares method and sum of error square was calculated by SPSS-17 statistical software.

\section{Results and Discussion}

3.1. Characterization of the Adsorbent. The characteristics of ANP are given in Table 1. The SEM and TEM of ANP are shown in Figure 2 indicating morphology of ANPs. The $\mathrm{X}$-ray diffraction analysis of the ANP was carried out and shown in Figure 3. The $d$ spacing was measured between the rows of atoms in crystal structure of ANP. The small peak formation indicated the nanocrystalline structure of the ANP. FTIR spectra (Figure 4) revealed that $\mathrm{O}-\mathrm{H}$ vibrations $3459 \mathrm{~cm}^{-1}$ due to the water in the lattice [21] and $\mathrm{O}-\mathrm{H}$ bending vibrations appear at $1644 \mathrm{~cm}^{-1}$. Weak bands are observed at $1386 \mathrm{~cm}^{-1}$ due to $\mathrm{Al}-\mathrm{O}$ bond vibrations. The bands at $1071 \mathrm{~cm}^{-1}$ and $846 \mathrm{~cm}^{-1}$ appear due $\mathrm{Al}-\mathrm{O}$ bonds [22]. BET surface area analysis shows that surface area of ANP is $82.91 \mathrm{~m}^{2} \mathrm{~g}^{-1}$ and the pore volume is $0.389 \mathrm{~cm}^{3} \mathrm{~g}^{-1}$; the density of ANP was determined and found to be $0.976 \mathrm{~g} \mathrm{~cm}^{-3}$.

3.2. Effect of Adsorbent Dose. To investigate the effect of adsorbent dose on adsorption of dye on ANP, the experiments were conducted with adsorbent dose between $0.1 \mathrm{~g}-12.5 \mathrm{~g}$ in $100 \mathrm{~mL}$ at $303 \mathrm{~K}$ and it was found that with an increase in the dose, the adsorption increases. This may be credited to the reason that at lower adsorbent dosage the number of dye molecules is comparatively higher as compared to availability of adsorption sites. The results are shown in Figure 5. It was observed that when adsorbent dose was doubled the percentage dye removal increased by a

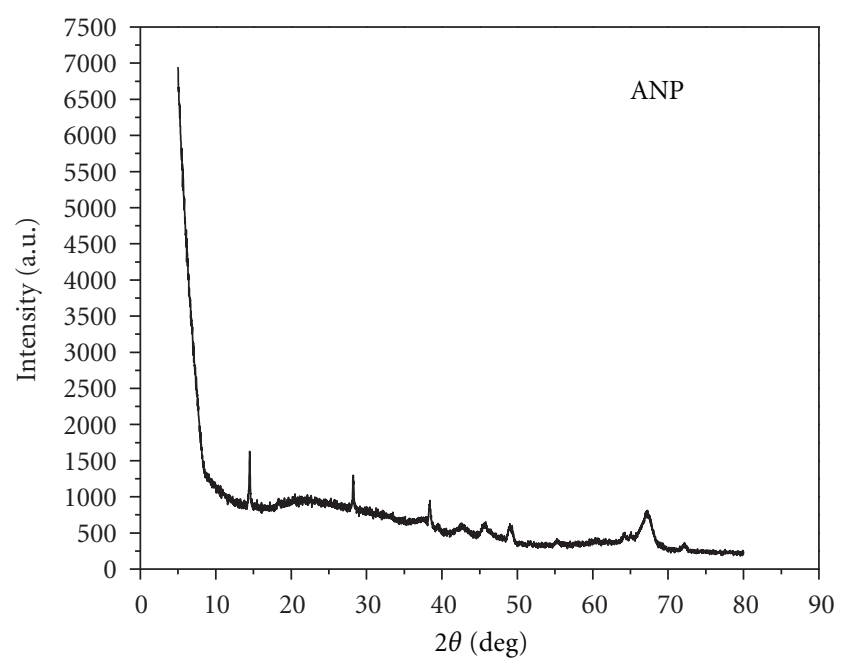

Figure 3: XRD of ANP.

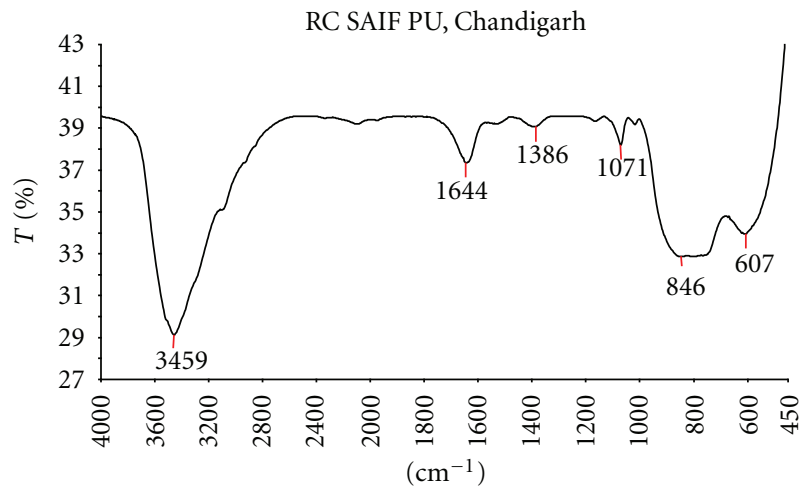

FIGURE 4: FTIR of ANP.

factor of 1.5. Almost optimum adsorption was observed at $0.1 \mathrm{~g}$ per $100 \mathrm{~mL}$.

3.3. Effect of $p H$. The dye adsorption is affected by solution $\mathrm{pH}$ and in the present study the effect of $\mathrm{pH}$ is studied in 


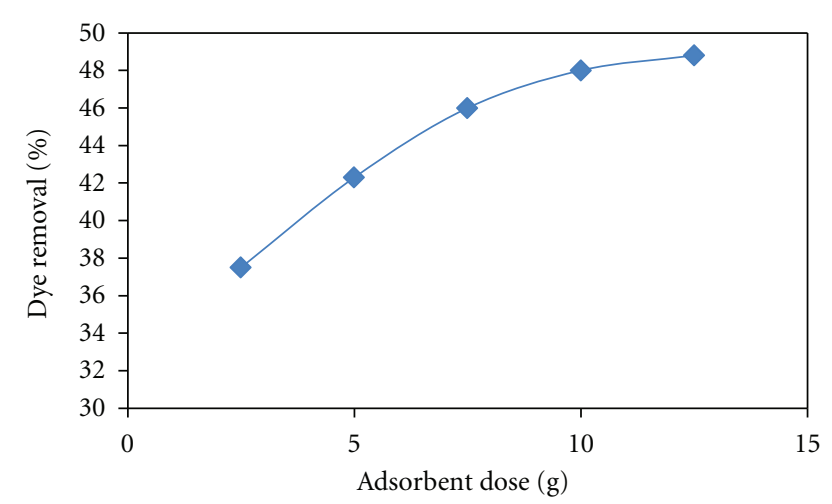

FigURE 5: Effect of adsorbent dose on percentage dye removal, 100 ppm dye concentration, $303 \mathrm{~K}, \mathrm{pH}=5$ of $\mathrm{AO}-7$.

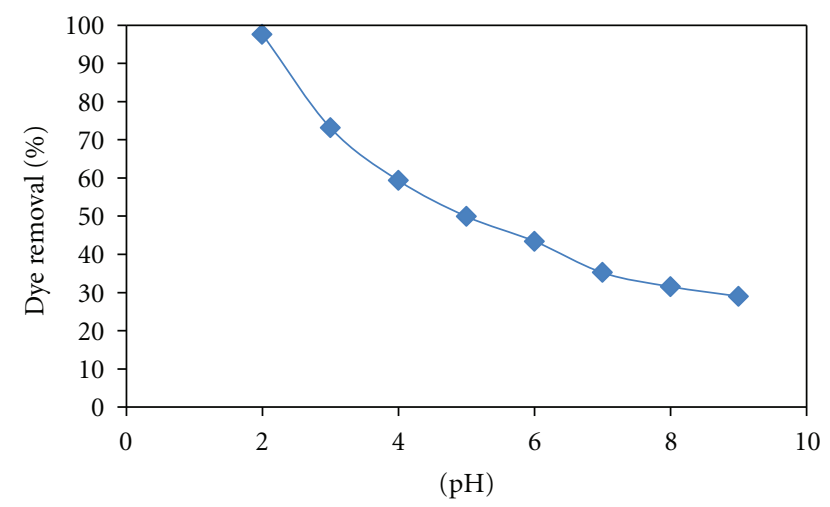

FIgURE 6: Effect of initial $\mathrm{pH}$ on percentage dye removal, $100 \mathrm{ppm}$ dye concentration, and $303 \mathrm{~K}$.

the range of 2-9 while initial concentration $\left(100 \mathrm{mg} \mathrm{L}^{-1}\right)$, adsorbent dose $(0.1 \mathrm{~g} / 100 \mathrm{~mL})$, and temperature $(303 \mathrm{~K})$ were kept constant. The effect of initial $\mathrm{pH}$ on the dye removal is shown in Figure 6. The adsorption capacity decreases when $\mathrm{pH}$ increases. The maximum adsorption of AO-7 occurs at $\mathrm{pH}$ 2. This may be ascribed to the reason that in the aqueous medium the functional groups such as hydroxyl groups develop on the surface which are protonated in acidic medium causing more electrostatic interactions between protonated ANP and anionic dye. The $\mathrm{pH}_{\mathrm{zpc}}$ measurement suggests that $\mathrm{pH}_{\mathrm{zpc}}$ for ANP is 8.0; thus beyond $\mathrm{pH}_{\mathrm{zpc}}$ negative charge develops on the surface so anionic dyes are best adsorbed below their $\mathrm{pH}_{\mathrm{zpc}}$. As the $\mathrm{pH}$ of the system increases the number of positively charged sites decreases; hence the adsorption of anionic dye also decreases. A positively charged site on the adsorbent favors the adsorption of anionic dyes due to electrostatic attractions.

3.4. Effect of Contact Time. The effect of contact time was investigated in the batch mode at dye concentration $100 \mathrm{mg} \mathrm{L}^{-1}$. The results have been shown in Figure 6 which suggests that the adsorption capacity of dyes increases with increasing contact time. The rate of dye removal is high initially due to high-concentration gradient and more availability of adsorption sites. The rapid transport of dye molecules from aqueous solution to the bulk makes the adsorption fast. The surface of ANP is charged and the net charge at the surface at a particular $\mathrm{pH}$ governs the adsorptive removal of dye from the solution.

3.5. Effect of Temperature. The effect of temperature on adsorption of AO-7 on was studied by carrying the temperature-controlled equilibrium experiments. The equilibrium adsorption capacity increases as a function of temperature as revealed by adsorption isotherms. The results advocate that the adsorption capacity of ANP increases with the increase in temperature suggesting that all the adsorption processes are endothermic in nature. The increase in adsorption at higher temperature can be attributed to the fact that at higher temperature kinetic energy of dye and water molecules increases in aqueous medium and the dye binds preferably to the active sites having higher surface area. The positive effect of temperature also indicates chemisorption [23] as a mode of binding of dye with ANP. Similar results have been found for the removal of basic dyes by other workers [23] suggesting that in this work the behavior of ANP towards dyes remains the same and the binding energy of adsorbate and adsorbent varies as the slope of different curves is different.

3.6. Adsorption Isotherms. The Freundlich, Langmuir, and Temkin isotherm models have been successfully applied to all of the above systems at various temperatures $303 \mathrm{~K}, 313 \mathrm{~K}$, and $323 \mathrm{~K}$ (Figure 7) and thermodynamic parameters are calculated accordingly. For the equilibrium concentration of adsorbate $\left(C_{e}\right)$ and amount of dye adsorbed at equilibrium $\left(q_{e}\right)$, the following linear forms of Langmuir (2), Freundlich (3), and Temkin (4) isotherms were studied.

Langmuir adsorption model is a well-known twoparameter model of adsorption. It has produced a good agreement with the experimental data suggesting the monolayer adsorption [24] of AO-7 on ANP.

In the Langmuir adsorption the primary binding forces are physical and it is assumed that adsorption capacity of all binding sites is equal and binding on one site does not affect another. $Q_{0}$ and $b$ are Langmuir constants in the following equation:

$$
\frac{1}{q_{e}}=\frac{1}{Q_{0}}+\frac{1}{b Q_{0} C_{e}} .
$$

$\mathrm{Q}_{0}\left(\mathrm{mg} \mathrm{g}^{-1}\right)$ and $b\left(\mathrm{~L} \mathrm{mg}^{-1}\right)$ indicate maximum dye uptake and Langmuir equilibrium constant, respectively. These isotherms characterize the equilibrium parameters of homogenous surfaces, monolayer adsorption, and allocation of adsorption sites. This isotherm fitted well on data (Table 2) suggesting that the adsorption of AO-7 on the active site does not affect the neighboring site. The values of $Q_{0}$ decrease with the increase of temperature due to increase in kinetic energy of dye molecules in aqueous medium. The essential characteristics of Langmuir isotherm can be calculated by using a dimensionless adsorption constant $R_{L}$ which can be defined as follows:

$$
R_{L}=\frac{1}{1+b C_{0}}
$$


TABLE 2: Adsorption isotherm and statistical comparison values of adsorption isotherm.

\begin{tabular}{lcccc}
\hline Isotherm model & $\begin{array}{c}\text { Isotherm } \\
\text { parameters }\end{array}$ & $303 \mathrm{~K}$ & $313 \mathrm{~K}$ & $323 \mathrm{~K}$ \\
\hline \multirow{4}{*}{ Freundlich } & $K_{F}$ & 1.223 & 1.228 & 3.154 \\
& $n$ & 0.9335 & 1.1664 & 2.0242 \\
& Std error & 0.00999 & 0.0317 & 0.0023 \\
& Std deviation & 0.02447 & 0.07766 & 0.0023 \\
& $t$ & -11.568 & -4.492 & 7.954 \\
\hline \multirow{4}{*}{ Langmuir } & $Q_{0}$ & 0.9766 & 0.8509 & 0.2086 \\
& $b$ & 1.3155 & 3.9425 & 11.517 \\
& $R$ & 0.98017 & 0.9516 & 0.9957 \\
& Std error & 0.00395 & 0.0037 & 0.00353 \\
& Std deviation & 0.0109 & 0.00906 & 0.00806 \\
& $t$ & 1.265 & 2.945 & 6.332 \\
\hline \multirow{4}{*}{ Temkin } & $a_{t}$ & 0.999 & 0.997 & 0.995 \\
& $b_{t}$ & 91.728 & 82.712 & 68.135 \\
& $R$ & 0.93377 & 0.9542 & 0.9884 \\
& Std error & 4.5236 & 2.8296 & 5.0095 \\
& Std deviation & 11.0805 & 6.9313 & 12.271 \\
$t$ & -8.646 & -13.527 & -9.111 \\
\hline & & & &
\end{tabular}

where $C_{0}$ is initial dye concentration. In this experiment the value of $R_{L}$ was found in the range of $0.00086-0.0075$ which lies between 0 and 1 suggesting favorable adsorption. The value of $R_{L}$ is very small suggesting that the size of adsorbent sites is uniform.

Freundlich isotherm is the earliest known two-parameter isotherm model based on the fact that exponentially decaying adsorption site energy distribution can be applied to nonideal sorption. $K_{F}$ and $n$ are Freundlich constants:

$$
\log q_{e}=\log K_{F}+\frac{1}{n} \log C_{e} .
$$

The Freundlich parameters calculated for the adsorption of AO-7 on ANP suggest that values of $n$ range between 0.93 and 2.02 , since the values of $1 / n$ for the process lie in the range 0 to 1.07. This indicates favorable adsorption [25]. The value of $K_{F}$ indicates adsorption capacity in $\mathrm{Lg}^{-1}$ and $K_{F}$ increases with the increase of temperature suggesting stronger binding forces operating at higher temperature between ANP and AO-7. On the basis of statistical analysis it is clear that Freundlich isotherm fits superiory on the process.

Temkin isotherm assumes that the fall in heat of adsorption of AO-7 on ANP would decrease linearly for the ANP and AO-7 interactions. The isotherm can be represented by the following linear form:

$$
q_{e}=\frac{R T}{b_{t}} \ln \left(a_{t} C_{e}\right),
$$

where $b_{t}$ is Temkin constant related to the heat of sorption $\mathrm{J} \mathrm{mol}^{-1}$ and $a_{t}$ is Temkin isotherm constant $\left(\mathrm{Lg}^{-1}\right)$. The

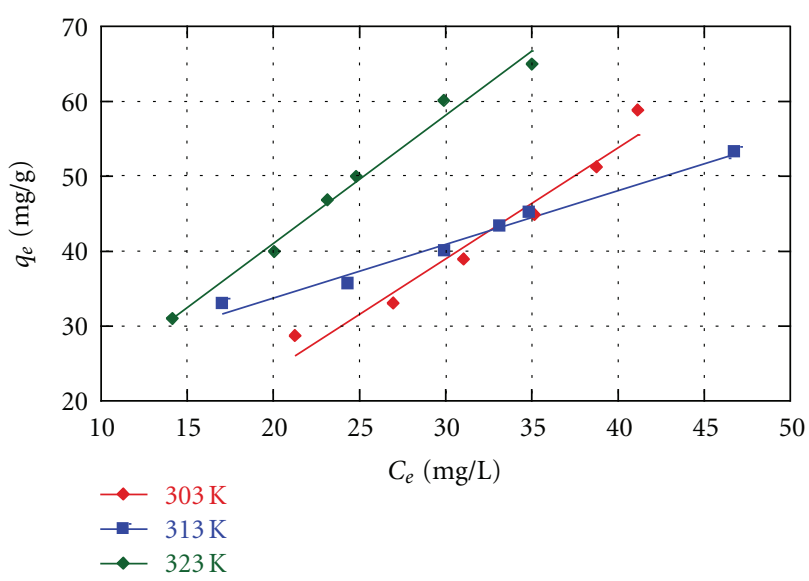

FIGURE 7: Adsorption isotherm plot of $C_{e}$ versus $q_{e}$ of AO-7 on ANP at $303 \mathrm{~K}, 313 \mathrm{~K}$ and $323 \mathrm{~K}$.

value of $a_{t}$ lies very close to 1.000 at all temperatures and $b_{t}$ decreases with the increase of temperature suggesting endothermic nature of the adsorption. Langmuir and Freundlich isotherms fitted the data better than Temkin as this is clear from the statistical analysis of the data.

The changes in the reaction on ANP expected during the process require the brief idea of the thermodynamic parameters which were also calculated from the above data using (6)-(8):

$$
\begin{gathered}
\Delta G^{\circ}=-R T \ln b, \\
\ln b=\frac{\Delta S^{\circ}}{R}-\frac{\Delta H^{\circ}}{R} \cdot \frac{1}{T},
\end{gathered}
$$

where $b$ is Langmuir equilibrium constant. The values $\Delta H^{\circ}$ and $\Delta S^{\circ}$ are determined from intercept and slope of (7). The values of thermodynamic parameters are given in Table 3 .

The Gibbs free energy, $\Delta G^{\circ}$, was found to be negative at all temperatures, indicating spontaneous process at all the temperatures while enthalpy, $\Delta H^{\circ}$, was positive suggesting endothermic and irreversible nature of the process. The positive value of entropy, $\Delta S^{\circ}$, suggests favorable randomness factor though its value is small. This suggests that in spite of small particle size of adsorbent the reaction is energetically favorable. The thermodynamic parameters were calculated and are given in Table 3.

\section{Kinetic Studies}

The rate of removal of AO-7 has been studied as a function of time on ANP as shown in Figure 6. The equilibrium was attained in $1 \mathrm{~h}$. Adsorption rate constant study was carried out with the famous Lagergren rate equation:

$$
\log \left(q_{e}-q_{t}\right)=\log q_{e}-\left(\frac{k_{1}}{2.303}\right) t .
$$

The pseudo-first-order equation (Figure 8) was evaluated. The $k_{1}$ was found to be $1.0319 \times 10^{-2} \mathrm{~min}^{-1}$. The suitable agreement was found between Pseudo first order data in 


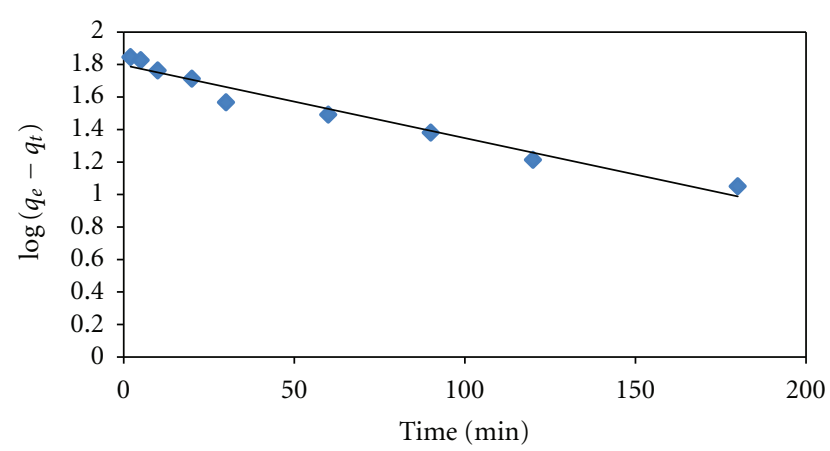

FIGURE 8: Lagergren plot for adsorption of AO-7 on ANP at $100 \mathrm{ppm}$ dye concentration, $303 \mathrm{~K}, \mathrm{pH}=5$.

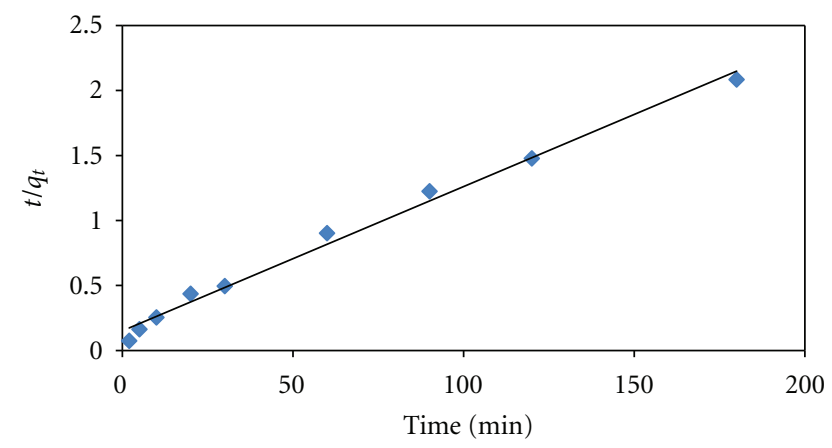

FIgURE 9: Pseudo second order kinetics plot for desorption of AO-7 on ANP, 100 ppm dye concentration, $303 \mathrm{~K}, \mathrm{pH}=5$.

statistical analysis, the correlation coefficient is high and standard error is low. The second-order equation was also tested on the whole range of time. The plot is shown in Figure 9 indicating the pseudo second order equation

$$
\frac{t}{q_{t}}=\frac{t}{k_{2} q_{e}^{2}}+\frac{1}{q_{e}} t
$$

The pseudo second order kinetic model fitted better than Lagergren model. The correlation constant was higher than first-order model. The rate constant $k_{2}$ was found to be $9.424 \times 10^{-4} \mathrm{mg} \cdot \mathrm{g}^{-1} \mathrm{~min}^{-1}$.

Elovich kinetic model (10) was also applied on the data to evaluate the possibility of chemisorption:

$$
q_{t}=\frac{1}{\beta} \ln (\alpha \beta)+\frac{1}{\beta} \ln t .
$$

The plot between $q_{t}$ versus $\ln t$ was a straight line. The regression coefficient was found to be 0.9855 ; a very small standard error was obtained. Several kinetic parameters are calculated for different models and represented in Table 4.

\section{Desorption Studies}

The desorption studies were also carried out. AO-7 was desorbed by using $1 \% \mathrm{w} / \mathrm{v} \mathrm{NaOH}$; it was found that the ANP can be used as adsorbent for more than 11 cycles without

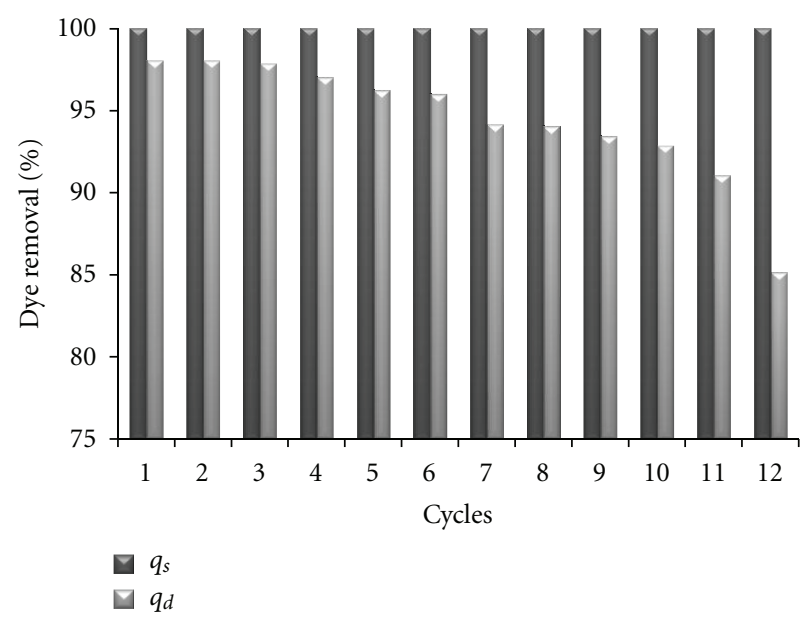

FIgURE 10: Quantity of dye accumulated in dye sorption desorption cycle.

TABLE 3: Thermodynamic parameters of adsorption of AO-7 on ANP.

\begin{tabular}{lccc}
\hline Temperature (Kelvin) & $\begin{array}{c}\Delta G^{\circ} \\
\left(\mathrm{J} \mathrm{mol}^{-1}\right)\end{array}$ & $\begin{array}{c}\Delta H^{\circ} \\
\left(\mathrm{J} \mathrm{mol}^{-1}\right)\end{array}$ & $\begin{array}{c}\Delta S^{\circ} \\
\left(\mathrm{J} \mathrm{K}^{-1} \mathrm{~mol}^{-1}\right)\end{array}$ \\
\hline 303 & -309.85 & & \\
313 & -3569.8 & +167.98 & +5.779 \\
323 & -6562.6 & & \\
\hline
\end{tabular}

TABLE 4: Comparison of kinetic constants for the adsorption of AO7 on ANP.

\begin{tabular}{lcc}
\hline Kinetic model & kinetic constants & Values \\
\hline Lagergren & $k_{1}$ & $0.01032 \mathrm{~min}^{-1}$ \\
model & $R$ & 0.9822 \\
& Std error & 2.582 \\
& Std deviation & 60747 \\
\hline \multirow{2}{*}{ Pseudo second } & $k_{2}$ & $9.424 \times 10^{-4} \mathrm{mg}^{-1} \mathrm{~min}^{-1}$ \\
order & $R$ & 0.9956 \\
& Std error & 2.267 \\
& Std deviation & 6.789 \\
\hline \multirow{4}{*}{ Elovich model } & $\alpha$ & 29.414 \\
& $\beta$ & 0.07127 \\
& $R$ & 0.9809 \\
& Std error & 0.6779 \\
\hline
\end{tabular}

much change of efficiency. The amount of desorbed dye was determined by using the following equation:

$$
q_{d}=\frac{\left(C_{d}-C_{s}\right) V}{W}
$$

where $C_{d}$ is concentration of dye after desorption and $C_{s}$ is concentration of dye after sorption. The results of sorption and desorption cycles are represented in Figure 10. The amount of dye desorbed was higher than the desorption 
results obtained for other adsorbents reported in the literature [26-29].

\section{Conclusion}

This study shows that AO-7 can be successfully removed from the aqueous solution by adsorption on ANP and this can be an effective and valuable mean for controlling water pollution due to dyes. The following conclusions can be drawn from this study. The batch adsorption experiments show that the adsorption of the AO-7 over ANP and its derivatives is dependent on $\mathrm{pH}$, amount of adsorbent, concentration, contact time, and temperature, and 100\% dye removal could be accomplished. The thermodynamic parameters obtained in both cases confirm the feasibility of the process at each concentration. The Freundlich, Langmuir, and Temkin isotherms fitted the data well. The results of kinetic experiments show that the adsorption proceeds via pseudo second order kinetics over all adsorbents. The desorption studied indicates that ANP can be used as speedy and efficient secondary treatment option.

\section{References}

[1] D. Chatterjee, B. Raj, and A. Mahata, "Adsorption and photocatalytic color removal using flyash and sunlight," Catalysis Communications, vol. 2, pp. 113-117, 2001.

[2] Y. M. Slokar and A. Majcen Le Marechal, "Methods of decoloration of textile wastewaters," Dyes and Pigments, vol. 37, no. 4, pp. 335-356, 1998.

[3] P. R. Gogate and A. B. Pandit, "A review of imperative technologies for waste water treatment technologies for waste water treatment II: hybrid methods," Advances in Environmental Research, vol. 8, pp. 501-551, 2004.

[4] N. H. Ince and G. Tezcanlí, "Reactive dyestuff degradation by combined sonolysis and ozonation," Dyes and Pigments, vol. 49, no. 3, pp. 145-153, 2001.

[5] J. P. Lorimer, T. J. Mason, M. Plattesand, and S. S. Phull, "Dye effluent decolorization using ultrasonically assisted electrooxidation," Ultrasonics Sonochemistry, vol. 7, pp. 237-242, 2000.

[6] X. Quan, X. Liu, L. Bo, S. Chen, Y. Zhao, and X. Cui, "Regeneration of acid orange 7-exhausted granular activated carbons with microwave irradiation," Water Research, vol. 38, no. 20, pp. 4484-4490, 2004.

[7] T. Robinson, G. McMullan, R. Marchant, and P. Nigam, "Remediation of dyes in textile effluent: a critical review on current treatment technologies with a proposed alternative," Bioresource Technology, vol. 77, no. 3, pp. 247-255, 2001.

[8] P. N. Dave, S. Kaur, and E. Khosla, "Removal of Eriochrome black-T by adsorption on to eucalyptus bark using green technology," Indian Journal of Chemical Technology, vol. 18, no. 1, pp. 53-60, 2011.

[9] P. N. Dave, S. Kaur, and E. Khosla, "Removal of basic dye from aqueous solution by biosorption on to sewage sludge," Indian Journal of Chemical Technology, vol. 18, no. 3, pp. 220-226, 2011.

[10] E. Khosla, S. Kaur, and P. N. Dave, "Surfactant modified tea waste as novel adsorbent for basic dye," Der Chemica Sinica, vol. 2, no. 5, pp. 87-102, 2012.

[11] E. Khosla, S. Kaur, and P. N. Dave, "Adsorption mechanism of basic red 12 over Eucalyptus bark and its surface derivatives,"
Journal of Chemical \& Engineering Data, vol. 57, no. 7, pp. 2004-2011, 2012.

[12] V. K. Gupta, A. Mittal, L. Krishnan, and V. Gajbe, "Adsorption kinetics and column operations for the removal and recovery of malachite green from wastewater using bottom ash," Separation and Purification Technology, vol. 40, no. 1, pp. 87-96, 2004.

[13] S. Karcher, A. Kornmüller, and M. Jekel, "Screening of commercial sorbents for the removal of reactive dyes," Dyes and Pigments, vol. 51, no. 2-3, pp. 111-125, 2001.

[14] J. Chen, W. Chen, and D. Zhu, "Adsorption of nonionic aromatic compounds to single-walled carbon nanotubes: effects of aqueous solution chemistry," Environmental Science and Technology, vol. 42, no. 19, pp. 7225-7230, 2008.

[15] A. Khaled, P. N. Kapoor, and K. J. Klabunde, "Nanocrystalline metal oxides as new adsorbents for air purification," Nanostructured Materials, vol. 11, pp. 459-468, 1999.

[16] K. Hristovski, A. Baumgardner, and P. Westerhoff, "Selecting metal oxide nanomaterials for arsenic removal in fixed bed columns: from nanopowders to aggregated nanoparticle media," Journal of Hazardous Materials, vol. 147, no. 1-2, pp. 265-274, 2007.

[17] Y. C. Sharma, V. Srivastava, and A. K. Mukherjee, "Synthesis and application of nano- $\mathrm{Al}_{2} \mathrm{O}_{3}$ powder for the reclamation of hexavalent chromium from aqueous solutions," Journal of Chemical and Engineering Data, vol. 55, no. 7, pp. 2390-2398, 2010.

[18] J. Hu, I. M. C. Lo, and G. Chen, "Fast removal and recovery of $\mathrm{Cr}(\mathrm{VI})$ using surface-modified jacobsite $\left(\mathrm{MnFe}_{2} \mathrm{O}_{4}\right)$ nanoparticles," Langmuir, vol. 21, no. 24, pp. 11173-11179, 2005.

[19] Y. C. Sharma, V. Srivastava, S. N. Upadhay, and C. H. Weng, "Alumina nanoparticles for the removal of $\mathrm{Ni}$ (II) from aqueous solutions," Industrial \& Engineering Chemistry Research, vol. 47, pp. 8095-8100, 2008.

[20] V. K. Gupta, A. Mittal, V. Gajbe, and J. Mittal, "Removal and recovery of the hazardous azo dye acid orange 7 through adsorption over waste materials: bottom ash and de-oiled soya," Industrial and Engineering Chemistry Research, vol. 45, no. 4, pp. 1446-1453, 2006.

[21] V. Srivastava, C. H. Weng, V. K. Singh, and Y. C. Sharma, "Adsorption of nickel ions from aqueous solutions by nano alumina: kinetic, mass transfer, and equilibrium studies," Journal of Chemical \& Engineering Data, vol. 56, pp. 1414-1422, 2011.

[22] W. T. Tsai, Y. M. Chang, C. W. Lai, and C. C. Lo, "Adsorption of ethyl violet dyes in aqueous solution by regenerated spent bleaching earth," Journal of Colloid and Interface Science, vol. 289, pp. 322-333, 2005.

[23] A. Vázquez, T. López, R. Gómez, Bokhimi, A. Morales, and O. Novaro, "X-ray diffraction, FTIR, and NMR characterization of Sol-Gel alumina doped with lanthanum and cerium," Journal of Solid State Chemistry, vol. 128, no. 2, pp. 161-168, 1997.

[24] V. K. Gupta, I. Ali, Suhas, and D. Mohan, "Equilibrium uptake and sorption dynamics for the removal of a basic dye (basic red) using low-cost adsorbents," Journal of Colloid and Interface Science, vol. 265, no. 2, pp. 257-264, 2003.

[25] A. Kumar, S. Kumar, S. Kumar, and D. V. Gupta, "Adsorption of phenol and 4-nitrophenol on granular activated carbon in basal salt medium: equilibrium and kinetics," Journal of Hazardous Materials, vol. 147, no. 1-2, pp. 155-166, 2007.

[26] S. V. Rodrigo and M. M. Beppu, "Dynamic and static adsorption and desorption of $\mathrm{Hg}$ (II) ionson chitosan membranes and spheres," Water Research, vol. 40, pp. 1726-1734, 2006. 
[27] O. Genç, L. Soysal, G. Bayramoğlu, M. Y. Arica, and S. Bektaş, "Procion green H-4G immobilizedpoly(hydroxyethylmethacrylate/chitosan) composite membranes for heavy metal removal," Journal of Hazardous Materials, vol. B97, pp. 111-125, 2003.

[28] G. Z. Kyzas and N. K. Lazaridis, "Reactive and basic dyes removal by sorption onto chitosan derivatives," Journal of Colloid and Interface Science, vol. 331, no. 1, pp. 32-39, 2009.

[29] S. W. Won and Y. S. Yun, "Biosorptive removal of Reactive Yellow 2 using waste biomass from lysine fermentation process," Dyes and Pigments, vol. 76, no. 2, pp. 502-507, 2008. 

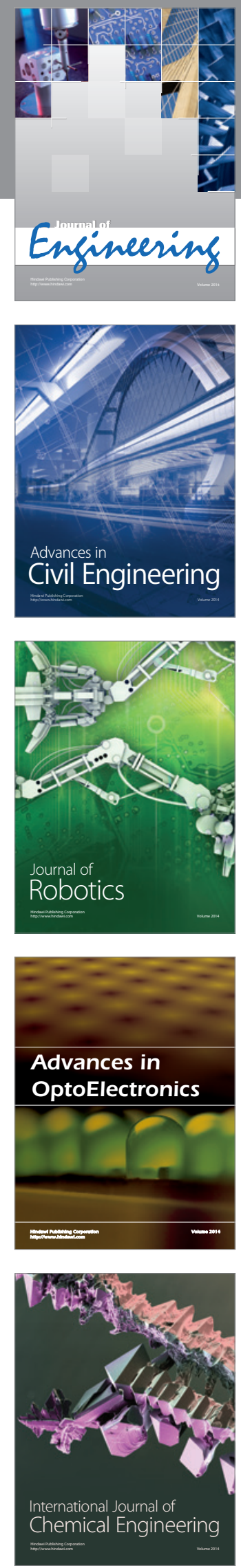

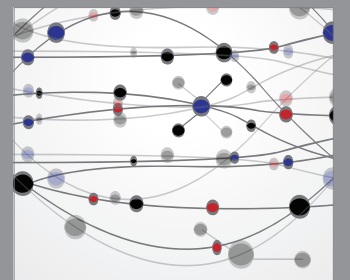

The Scientific World Journal
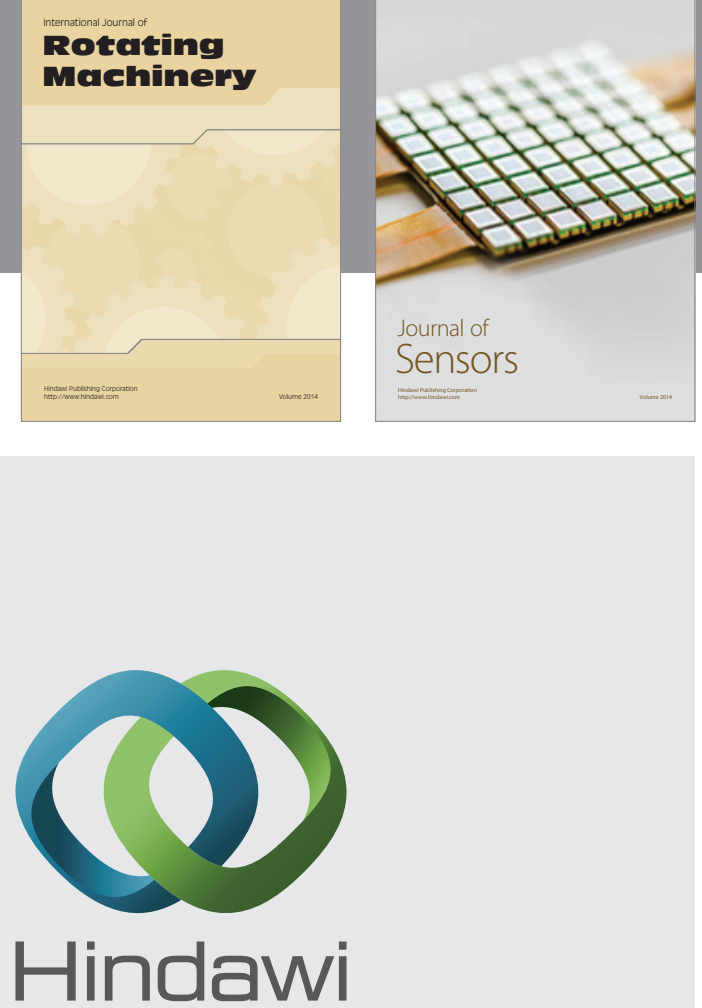

Submit your manuscripts at http://www.hindawi.com
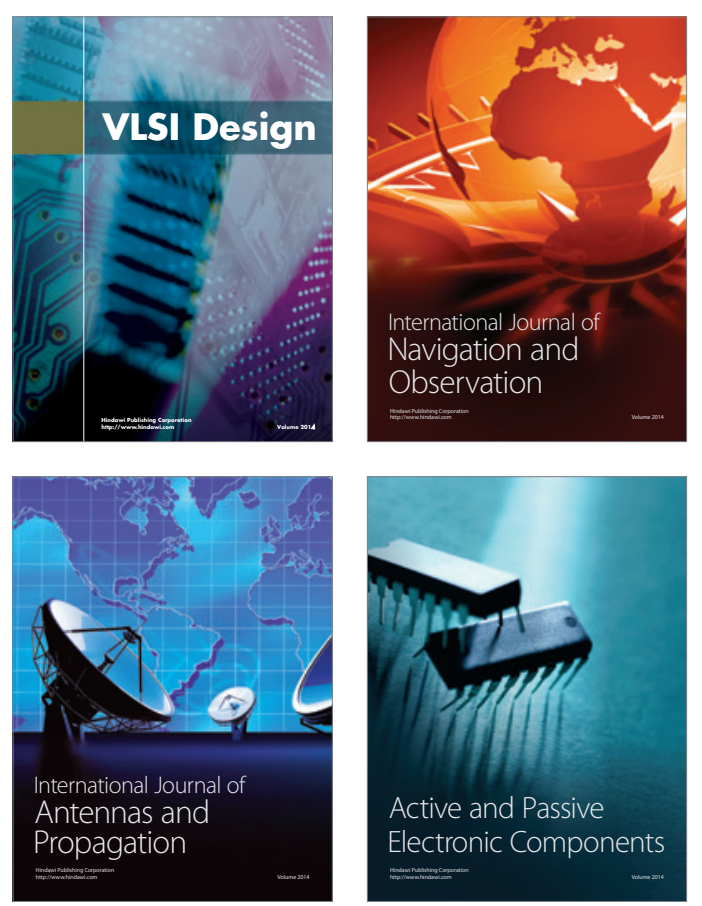
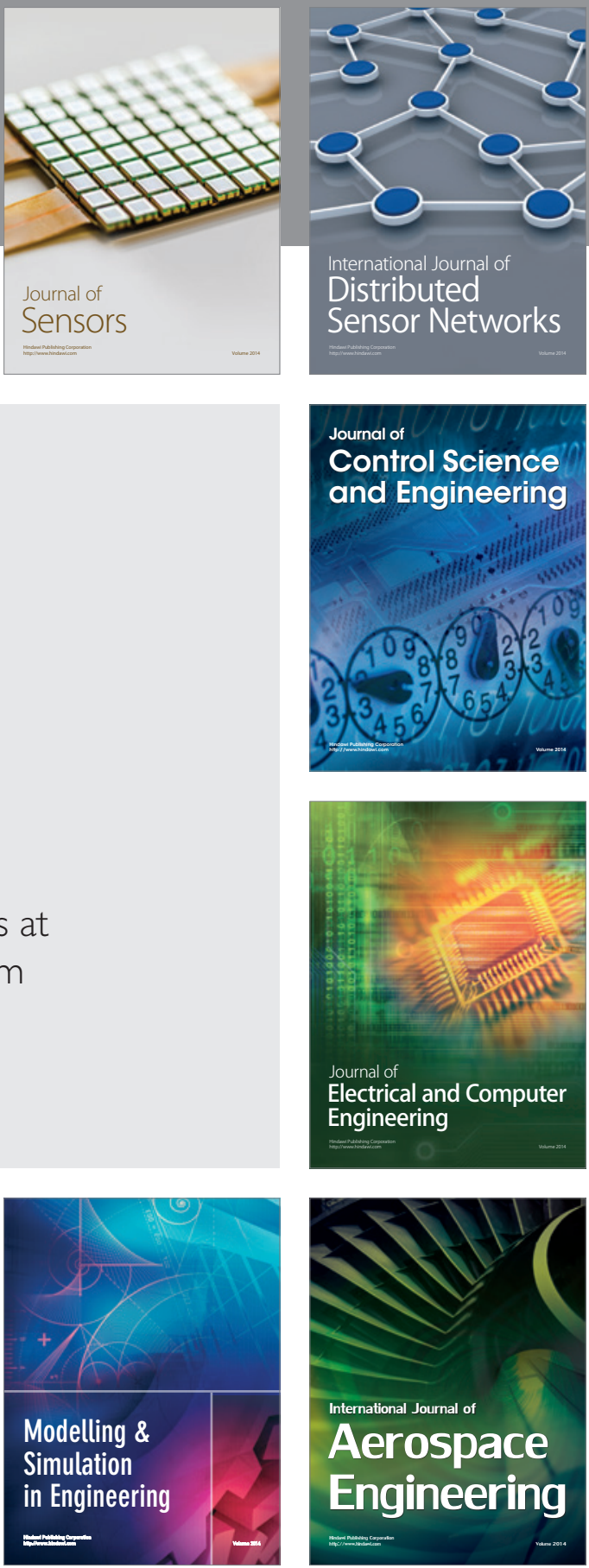

Journal of

Control Science

and Engineering
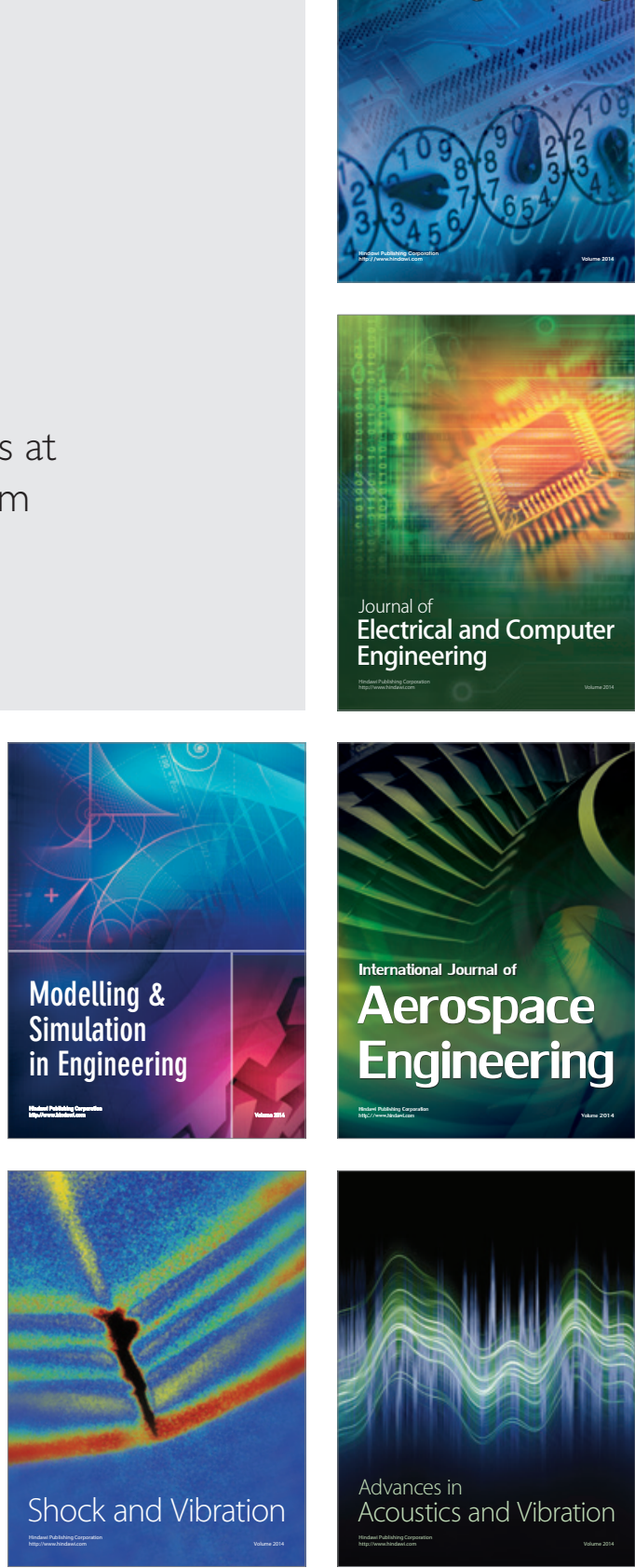